\title{
Asymmetric Effects of Monetary Policy in the United States
}

\author{
Morten O. Ravn and Martin Sola
}

$\mathbf{T}$ his paper tests for the presence of asymmetric effects of monetary policy on aggregate activity using U.S. postwar quarterly data. We are interested in three types of asymmetry: (i) whether negative and positive monetary policy shocks have different effects on output; (ii) whether big or small shocks have different effects; and/or (iii) whether low-variance, negative shocks have asymmetric effects on output. We discuss the three possibilities below and explain under which conditions these asymmetries might take place. ${ }^{1}$

To date, the empirical literature has focused on a particular asymmetry that we call "the traditional Keynesian asymmetry," which states that positive monetary policy shocks have smaller real effects than negative monetary policy shocks - or, in a more extreme form, that only the latter shocks have real effects. This asymmetry can be derived under the assumption of either downward (upward) sticky (flexible) nominal wages or sticky prices together with rationing of demand.2,3

\footnotetext{
1 Other types of asymmetric effects have been explored by Garcia and Schaller (1995), who examine whether monetary policy affects output differently in different phases of the business cycle, and Ravn and Sola (1997), who look at the effects of monetary policy on transitional dynamics. Hooker and Knetter (1996) analyze whether military procurement spending has asymmetric effects on employment, and they find that "big" negative shocks to procurement have proportionally larger effects on employment growth than large positive shocks or small shocks to procurement. Hooker (1996) examines whether there are asymmetries in the relationship between oil-price shocks and U.S. macroeconomic variables. He finds that the asymmetric effects in this relationship are fragile. Here we focus on the relationship between monetary policy shocks and aggregate activity. Lo and Piger (2003) examine regime switching in the response of U.S. output to monetary policy. They find evidence of such time variance and show that policy actions during recessions have larger output effects than policy actions during expansions.

2 Cover (1992) and DeLong and Summers (1988) have tested for this asymmetry in U.S. data: Cover (1992) finds firm support for the
}

We also consider asymmetric effects that are implied by models with menu costs (see, among others, Ball and Romer, 1990, and Ball and Mankiw, 1994). In static (deterministic) settings, standard menu-cost models imply that "big" monetary policy shocks are neutral because firms would find it optimal to adjust nominal prices, while "small" monetary policy shocks would have real effects because keeping nominal prices fixed is associated with only a second-order cost. In other words, the firms have to decide-before the monetary policy shock is observed-whether to index their prices (at the cost of paying the menu cost) or not. Firms will choose indexation (which implies neutrality) only if the variance of monetary policy shocks is high. We extend the analysis by assuming that the monetary policy process can change between having a "high" variance and a "low" variance. This approach allows for identifying periods of neutrality and periods of non-neutrality.

Finally, we consider the case in which only small

Morten O. Ravn is a professor at the London Business School and a research fellow at the Centre for Economic Policy Research. Martin Sola is a professor at the Universidad Torcuato di Tella and Birkbeck College, University of London. The authors thank Mark Hooker and Paul Evans for detailed comments and James Peery Cover for provision of data, as well as Charlie Bean, Michael Beeby, Paul Beaudry, John Driffill, Svend Hylleberg, Haris Psaradakis, Danny Quah, Ron Smith, Howard Wall, and seminar participants at the Bank of England, London School of Economics, University of Aarhus, Universitat Pompeu Fabra, Warwick University, the 1996 Econometric Society meeting in Istanbul, and the 1997 conference on Modelisation Macroeconometrique Dynamique at University Evry-Val d'Essonne, Paris.

Federal Reserve Bank of St. Louis Review, September/October 2004, 86(5), pp. 41-60

(1) 2004, The Federal Reserve Bank of St. Louis. 
negative shocks to nominal demand affect real aggregate activity. Consider a dynamic menu-cost model in which there is positive steady-state inflation; firms can change prices costlessly every second period, but, if firms want to change prices in between the two periods, they must pay the menu cost. This gives rise to an asymmetric pricing rule in which "inaction" is optimal for a wider range of negative shocks than positive shocks. We call this case the "hybrid" asymmetry because it has similarities both to the traditional Keynesian asymmetry and to the menu-cost asymmetry.

To test for the asymmetric effects described above, we use a procedure that consists of estimating a monetary policy process that allows for changes in regime using the regime-switching model of Hamilton (1988) appropriately modified to our setting. We assume that the money supply is a regimeswitching process that allows for changes in the mean and in the variance of the innovations to the process. This implies that we can distinguish between four different shocks to monetary policy: big positive shocks, big negative shocks, small positive shocks, and small negative shocks. The distinction between "big" and "small" here refers to the variance of the innovations in the two states.

This technique allows us to test for the existence of the three cases of asymmetric effects discussed above. We estimate a simultaneous system consisting of a monetary policy equation and an output equation, which includes the (change in the) current unanticipated shocks from the "monetary policy" relationship. We then test for asymmetries by introducing various parameter restrictions on the four different types of unanticipated monetary policy shocks in the output equation and by applying likelihood ratio tests.

We investigate two different sets of quarterly data for the U.S. postwar period. First we examine a data set for the period 1947-87, considered previously by Cover (1992), using M1 as the key monetary variable. The second set of data is for the period 1960-95, previously examined by, among others, Christiano, Eichenbaum, and Evans (1996). Here we measure monetary shocks on the basis of (the negative of) the federal funds rate. ${ }^{4}$ The motivation for using the federal funds rate rather than M1 (or other money supply measures) is that the federal

\footnotetext{
4 We use the negative of the federal funds rate because a positive (negative) money-supply shock corresponds to a loosening (tightening) of monetary policy.
}

funds rate is widely recognized to be one of the primary monetary policy variables and is probably a more stable measure of monetary policy than M1.

Using the first set of data, we find that there have indeed been regime changes in the money-supply relationship. We find a low-growth, low-variance regime that spans the period from 1947 to around 1967 and a high-mean, high-variance regime that takes over for the majority of the period after 1968. When we test for the presence of asymmetric effects, we find that negative unanticipated money-supply shocks have greater real effects than positive unanticipated money-supply shocks.

Using the federal funds rate as the measure of monetary policy gives rise to different results. Again, the monetary policy process is divided into two regimes: one with a low mean and a low variance and another with a high mean and a high variance. The classification of the regimes is very different when M1 is used. The low-mean, low-variance regime occurs for most of the sample. The other regime dominates for a short period in the mid-1970s and the Volcker period. When we test for asymmetric effects using these alternative data, we find strong evidence in favor of the "hybrid asymmetry" (i.e., that only small negative monetary policy shocks have real effects). This finding is in line with the menu-cost model. 5

The remainder of the paper is organized as follows. In the second section we look into the implications for asymmetric effects of standard menu-cost models. The third section is devoted to a description of the empirical method that we will apply. In the fourth section we examine the two alternative sets of U.S. data and test for the presence of asymmetries. In the fifth section we summarize and draw some conclusions.

\section{THEORETICAL CONSIDERATIONS}

First, to motivate and clarify the empirical analysis, we consider some of the theoretical possibilities for asymmetric effects of nominal demand on real output.

\footnotetext{
Since we wrote this paper, a number of authors have examined these issues using slightly different techniques. Agénor (2001) examines the evidence on asymmetries using a vector autoregression (VAR) technique. He finds asymmetries for four emerging markets. Senda (2001) uses a panel technique to examine whether the degree of asymmetry is related to the magnitude of trend inflation and the variability of nominal gross domestic product (GDP) growth. Weise (1999) also applies a VAR technique focusing on asymmetries over the business cycle but also finds asymmetries in the response to money shocks of different sizes.
} 
In the Keynesian literature building on sticky wages or sticky prices, the natural candidate for asymmetric effects is related to different real effects of positive and negative changes in nominal demand. Consider a model with downward (upward) sticky (flexible) nominal wages. Assume that the labor market initially clears at the nominal wage that corresponds to the price level (and expected price level) consistent with the current-level nominal demand and that the long-run supply curve is vertical. This implies that the supply curve will be vertical at the expected price level but positively sloped for price levels below the expected price level. Hence, unanticipated increases in nominal demand will be neutral, but unanticipated decreases in nominal demand will be associated with lower output and employment.

The problem with the analysis above is the lack of clear microeconomic foundations. Economic agents may adjust to the economic environment, and this can have implications for the result on asymmetric effects. Hence, it is important to consider models in which decision rules are explicitly derived. We will consider whether such asymmetries can arise in menu-cost-type models and derive the specific types of non-linearities in the relationship between activity and nominal demand. ${ }^{6}$

Here we follow the presentation in Ball and Romer (1990) and Ball and Mankiw (1994). Consider an economy with many price-setting agents, each of whom acts as a producer/consumer. Each agent produces a single differentiated good, which is sold at the nominal price, $P_{i}$. It is assumed that there is a small menu cost, denoted by $s>0$, of changing nominal prices. Let the utility of agent $i$ be given as

$$
U_{i}=G\left(Y, \frac{P_{i}}{P}\right)-s D_{i}
$$

where $Y$ denotes aggregate real spending, $P$ is the aggregate price level, and $D_{i}$ is a dummy variable that equals 1 if prices are changed and 0 otherwise. We assume that velocity is equal to unity, i.e., $Y=M / P$, where $M$ denotes the nominal money stock. Equation (1) can then be written as

$$
U_{i}=G\left(\frac{M}{P}, \frac{P_{i}}{P}\right)-s D_{i} .
$$

\footnotetext{
6 Akerlof and Yellen (1985), Mankiw (1985), and Blanchard and Kiyotaki (1987) have analyzed how menu-cost models (or near-rationality) may affect the pricing decisions of firms and how this affects the real effects of changes in nominal demand.
}

In the absence of menu costs $(s=0)$, the first-order condition for each agent is that $G_{2}\left(\frac{M}{P}, \frac{P_{i}^{*}}{P}\right)=0$, where $G_{2}$ denotes the derivative of $G$ with respect to the second argument. In this case, in a symmetric equilibrium, changes in $M$ are neutral. Such a symmetric equilibrium is assumed to exist and corresponds to $M=P=P_{i}=1 .{ }^{7}$ Consider now an experiment where prices of all producers are set according to an expected money supply equal to 1 , but after this $M \neq 1$ is realized. Each producer decides whether to pay the menu cost (setting prices equal to $P_{i}^{*}$ ), in which case money is neutral, or maintain prices $\left(P_{i}\right)$, in which case money has real effects. Assume, first, that every price-setter except $i$ expects all other price-setters not to change prices. The utility of not changing the price for agent $i$ is then given as $U^{N A}=G(M, 1)$. If the agent decides to change the price of good $i$, utility is given by $U^{C P}=$ $G\left(M, P_{i}^{*} / P\right)-s$. Hence, inaction is an equilibrium if

$$
U^{N A}-U^{C P}>0 \Rightarrow G\left(M, \frac{P_{i}^{*}}{P}\right)-G(M, 1)<s .
$$

This condition implies that there is a range of money supplies for which inaction is a possible equilibrium. ${ }^{8}$ Making a second-order Taylor approximation around $M=1$, it can be shown that this range is given when

(4) $M$ lies in the interval

$$
\left(1-M^{*} ; 1+M^{*}\right), M^{*}=\sqrt{\frac{-2 G_{22} s}{G_{12}^{2}}} .
$$

The range of money-supply shocks for which neutrality appears is given when

(5) $M$ lies in the interval $\left(-\infty ; \mathrm{M}^{* *}\right)$ and/or $\left(\mathrm{M}^{* *} ; \infty\right)$,

$$
M^{* *}=\sqrt{\frac{-2 s}{G_{22}}} .
$$

Thus, small money-supply changes have real effects when $M$ lies in the interval $\left(1-M^{*} ; 1+M^{*}\right)$; "big" changes are neutral when $M$ lies in the interval $\left(-\infty ; \mathrm{M}^{* *}\right)$ and/or $\left(\mathrm{M}^{* *} ; \infty\right)$. Hence, with menu costs and no other features, it is the size of the change in nominal demand that matters.

\footnotetext{
7 Strictly speaking, one also needs to assume that the second-order condition is fulfilled and that the equilibrium is stable (i.e., $G_{22}(1,1)<0$ and $\left.G_{12}(1,1)>0\right)$.

8 It is possible that this range overlaps with a range of money supplies
} for which it is also optimal for all agents to change prices. 
Above, the changes in money supply are zeroprobability events. Alternatively, assume that money supply is a stochastic process with a mean $M$ and a variance $\sigma^{2}$ and that agents must decide whether to pay the menu cost before observing the current money-supply shock. Thus, by construction, agents choose either indexation or non-indexation. Ball and Romer $(1989,1990)$ show that in this model non-indexation is an equilibrium for

$$
E G\left(\frac{M}{P_{0}}, \frac{P_{i}^{*}}{P_{0}}\right)-E G\left(\frac{M}{P_{0}}, 1\right) \simeq-\frac{G_{12}^{2}}{2 G_{22}} \sigma^{2}<s,
$$

where $1 / P_{0} \simeq 1-\sigma^{2} G_{211}^{2} /\left(2 G_{22}\right)$. The difference between this case and the analysis above is that the decision of whether to pay the menu cost is determined by the variance of the money-supply shock. If the variance is high, money is neutral because firms perceive that there is a high probability of a big shock, while money has real effects if the variance is low. Thus, monetary policy is either always neutral or always non-neutral. This is a rather negative result since the theory as such does not have any testable (time-series) implications.

This latter implication can be overturned by a slight modification. Assume that the money supply can switch between two states of nature. In state $i$ the variance of the money supply is $\sigma_{i}^{2}$ and $\sigma_{1}^{2}>\sigma_{0}^{2}$. Let us also assume that the state variable that dictates the variance of the money supply follows a first-order Markov process. Let $\pi_{i j}$ be the probability that, given that the observed state today is $i$, the realized state tomorrow is $j$. The probability transition matrix is given by

$$
\Pi=\left[\begin{array}{ll}
\pi_{00} & \pi_{01} \\
\pi_{10} & \pi_{11}
\end{array}\right],
$$

where each row sums to 1 . Assume also that agents observe the current state when setting the initial price and when deciding whether to pay the menu cost or not. Then, using the same reasoning as above shows that inaction is an equilibrium when

$$
-\frac{G_{12}^{2}}{2 G_{22}}\left(\pi_{00} \sigma_{0}^{2}+\pi_{01} \sigma_{1}^{2}\right)<s
$$

when the current state is 0 and

$$
-\frac{G_{12}^{2}}{2 G_{22}}\left(\pi_{10} \sigma_{0}^{2}+\pi_{11} \sigma_{1}^{2}\right)<s
$$

when the current state is 1 .
There are two possible outcomes here. If (i) the difference between $\sigma_{0}^{2}$ and $\sigma_{1}^{2}$ is small or (ii) either $\pi_{01}$ or $\pi_{10}$ is close to 1 , there will be either indexation or non-indexation in both states. If there is a nontrivial difference between the two variances and the states are relatively persistent, there will be indexation if today's state is 1 and non-indexation if today's state is 0 . Hence, as in the standard menucost model, firms' actions depend on the monetary policy that they observe and their expectations of tomorrow's monetary policy.

Ball and Mankiw (1994) analyze a menu-cost model in which firms face a two-period problem and in which there is positive steady-state inflation (equal to $\dot{p}$ ). Each firm initially sets a price that can be changed next period, subject to a menu cost. They also assume the loss functions are quadratic such that, for a big enough menu cost, firms will choose a price that equals half the steady-state inflation rate in both periods. ${ }^{9}$ If an unanticipated shock arrives in period 1, it might be optimal for firms to pay the menu cost and change prices. Since the optimal price in period $1(\dot{p})$ is already above the price set at period $0(\dot{p} / 2)$, it is clear that positive disturbances will lead to a greater incentive to change prices than negative disturbances. They show that in a quadratic setup, the range of non-action is given when $M$ lies in the interval $(-\sqrt{s}-\dot{p} / 2 ; \sqrt{s}-\dot{p} / 2)$, which is symmetric around $-\dot{p} / 2$ but asymmetric around 0 . The model therefore implies an asymmetry that is similar to both the basic menu-cost results discussed above and to the traditional Keynesian asymmetry. We call this "hybrid" asymmetry. ${ }^{10}$

Finally, it is worth mentioning that imperfections in the labor market such as the existence of efficiency wage considerations or insider-outsider phenomena can be coupled with the menu-cost models. This has been investigated by Akerlof and Yellen (1985) and Ball and Romer (1990), and the

\footnotetext{
9 If we let $\dot{p}$ denote the steady-state inflation rate, then with a quadratic loss function it is optimal to set prices at $\dot{p} / 2$ in both periods, given that $s>\dot{p}^{2} / 2$.

10 Senda (2001) shows that the degree of asymmetry depends on the mean trend inflation rate and the variability of aggregate demand. Senda finds that the degree of asymmetry is non-trivially related to the mean inflation rate, increasing for low-to-moderate inflation rates but decreasing for high inflation rates. The reason for this is that, as inflation rates become very large, the cost of two-period price-setting becomes very large (in expected terms) and firms thus realize that they will probably want to change prices in the intermediate period. In this case, the asymmetry may become very small, although it still persists qualitatively. Senda also provides some favorable evidence of this hypothesis based on a panel of prewar and postwar data.
} 
literature has shown that real rigidities increase the importance of nominal rigidities.

The cases discussed above relate to how different monetary policy shocks affect output. An alternative asymmetry is that monetary policy may affect aggregate activity differently during booms compared with recessions. Credit and liquidity may be readily available in booms, and it is likely that monetary shocks during these periods are neutral. In recessions, however, firms and consumers may find it harder to obtain funds and monetary policy might have real effects through the credit and liquidity channels. This is the mechanism examined in the research on financial market imperfections (see, e.g., Bernanke and Gertler, 1989, Gertler, 1992, Greenwald and Stiglitz, 1993, and Shleifer and Vishny, 1992). Although this possible asymmetry is of great interest, we shall not address it here but will concentrate on the above versions of asymmetric effects.

\section{EMPIRICAL METHODOLOGY}

In this section we describe our empirical methodology, which is related to the procedure used for testing the New Classical theories of informationbased non-neutralities (developed by Lucas, 1972, 1975) in Barro (1977, 1978), Barro and Hercowitz (1980), Boschen and Grossman (1982), and, in particular, Mishkin (1982). Two relationships are estimated simultaneously. The first of these is a monetary policy relation from which one obtains estimates of the anticipated and unanticipated monetary policy shocks. These shocks then feed into an aggregate output equation. DeLong and Summers (1988) and Cover (1992) test whether positive and negative unanticipated monetary policy shocks have different effects on real activity and find strong support for the traditional Keynesian asymmetry in U.S. data.

Cover's (1992) methodology can be summarized as follows. First, one estimates simultaneously

$$
\Delta m_{t}=\Phi(L) \Delta m_{t-1}+\Theta x_{t-1}+\varepsilon_{t}
$$

and

$$
\Delta y_{t}=\psi z_{t}+\beta^{+} \varepsilon_{t}^{+}+\beta^{-} \varepsilon_{t}^{-}+\xi_{t}
$$

where $\Delta$ is the first-difference operator, $m_{t}$ is the measure of the monetary policy, $\Phi(L)$ is a lag polynomial, $\Theta$ is a vector of parameters, $x_{t-1}$ is a vector of predetermined regressors that reflects possible endogenous policy responses (and includes variables such as unemployment, changes in the monetary base, changes in output, government budget surpluses, changes in interest rates, and inflation), $y_{t}$ is the measure of real aggregate activity, $\psi$ is a parameter vector, $Z_{t}$ is a vector of regressors (which includes lagged changes in output and lagged changes in the Treasury bill rate), and $\varepsilon_{t}^{+}$and $\varepsilon_{t}^{-}$are the positive and negative parts of $\varepsilon_{t}$ from equation (9), defined as

$$
\varepsilon_{t}^{+} \equiv \max \left(0, \varepsilon_{t}\right), \varepsilon_{t}^{-} \equiv \min \left(0, \varepsilon_{t}\right) .
$$

Equation (9) is the monetary policy process and equation (10) is the aggregate output equation. The asymmetry hypothesis is a test of whether $\beta^{+}$equals $\beta^{-}$; rejection of this restriction, together with $\beta^{+}$ being insignificantly different from zero and $\beta^{-}$ significantly different from zero, supports the hypothesis. ${ }^{11}$

We extend this methodology along two lines. First, on the basis of the theory presented in the previous paragraph, we impose that monetary impulses have only temporary effects on the level of output. Because the output series we use here has a unit root, we stick to modeling the growth rate of output; but we change the specification of this equation 12 to

$$
\Delta y_{t}=\psi z_{t}+\beta\left(e_{t}-e_{t-1}\right)+\xi_{t},
$$

where $\beta$ is a vector of parameters and $e_{t}$ is a vector of unanticipated money shocks specified later in the paper. This specification implies that any unanticipated shock associated with monetary policy will increase output only temporarily, exactly as stated in the theories that we have discussed.

Second, we differentiate not only positive and negative monetary policy shocks, but also big and small shocks. As made clear above, in a stochastic menu-cost model the relevant distinction between big and small is based on the variance of the unanticipated monetary policy shock. Hence, we estimate a monetary policy relationship that allows for this distinction, as a discrete-state regime-switching model. ${ }^{13}$

\footnotetext{
11 Note that according to the specification of the money-supply equation and the output equation, money supply reacts to lagged variables, while output reacts to current monetary shocks. This assumption is contrary to standard assumptions made in the VAR literature but can be justified on the basis that the monetary authority may not have information on current output, while "true" real activity may be affected by actual current changes in monetary policy. We make this assumption mainly to make the analysis comparable to the previous contributions on asymmetries.

${ }^{12}$ We thank Paul D. Evans for pointing out the need to specify the system to account for the latter point.

${ }^{13}$ Such a technique has been used widely to characterize movements that arise when the moments of the variables under scrutiny change behavior over time; see, e.g., Hamilton (1988, 1989, 1990), Phillips (1991), Sola and Driffill (1994), and Ravn and Sola (1995). The basic elements of the method are described extensively in Hamilton (1994).
} 
According to the regime-switching methodology, a time series is modeled as having discrete changes in its unconditional mean and/or variance and the changes in regime are dictated by an unobservable discrete-valued state variable, $s_{t}=0,1$. We also add to the switching regression a set of conditioning variables that are not subject to regime changes. With this modification, we estimate a monetary policy equation that allows for changes in mean and variance. This leads us to the following specification:

$$
\begin{aligned}
& \left(\Delta m_{t}-\mu\left(s_{t}\right)\right) \\
& =\Phi(L)\left(\Delta m_{t-1}-\mu\left(s_{t-1}\right)\right)+\Theta x_{t-1}^{\prime}+\sigma\left(s_{t}\right) \eta_{t},
\end{aligned}
$$

where $\Phi(L)$ is a lag polynomial, $\Theta$ is a vector of parameters, $x_{t-1}^{\prime}$ is a vector of de-meaned predetermined variables (we include as regressors the log difference of non-borrowed reserves, the log difference of total reserves, the log difference of GDP, and the log difference of the implicit GDP deflator) ${ }^{14}$ defined as $x-\mu_{x}, \mu\left(s_{t}\right)$ is a state-dependent mean, $s_{t}$ is the discrete-valued state variable, and $\eta_{t}$ is an i.i.d. $N(0,1)$ error term that is independent of $s_{t}$.

The monetary policy process can have two different means, $\mu_{0}$ and $\mu_{1}$, with associated variances $\sigma_{0}^{2}$ and $\sigma_{1}^{2}$. In the practical application these are estimated as $\mu_{0}+\Delta \mu s_{t}$ and $\sigma_{0}+\Delta \sigma s_{t}$. It is assumed that the (unobserved) states are generated by a twostate Markov process. Let $\pi_{i j}$ be defined as $\pi_{i j}=$ $P\left(s_{t}=i \mid s_{t-1}=j\right), i, j=0,1$. The probability transition matrix is given as

$$
\Pi=\left(\begin{array}{ll}
\pi_{00} & \pi_{01} \\
\pi_{10} & \pi_{11}
\end{array}\right)
$$

where each of the transition probabilities is restricted to be non-negative and belongs to the unit interval. ${ }^{15}$

The division into big and small shocks is done as follows. Consider the expected money growth in period $t$, given information available at time $t-1$ and assuming momentarily that the information set

\footnotetext{
${ }^{14}$ We de-mean the non-switching exogenous variables so that $\mu\left(s_{t}\right)$ can be interpreted as the unconditional mean of money growth.

15 Note that we do not allow for regime switching in the exogenous variables. To allow these variables to have changes in regime will require imposing either that they all switch simultaneously with the money supply (see, e.g., Sola and Driffill, 1994) or that each variable is allowed to switch independently (see, e.g., Ravn and Sola, 1995). The first approach is applicable when the variables are closely related (for example, for interest rates of bonds of different maturities), but does not naturally occur in the present analysis. The second approach has the disadvantage that the increase in the number of states quickly makes it intractable.
}

includes the realization of the states. Expected money growth is given as

$$
E_{t-1}^{*} \Delta m_{t}=\left(\mu_{0}+\Phi\left(\Delta m_{t-1}-\left(\mu_{0}+\Delta \mu \pi_{01}\right)\right)+\Theta x_{t-1}\right)
$$

if $s_{t}=0$ and

$$
E_{t-1}^{*} \Delta m_{t}=\left(\mu_{0}+\Delta \mu+\Phi\left(\Delta m_{t-1}-\left(\mu_{0}+\Delta \mu \pi_{11}\right)\right)+\Theta x_{t-1}\right)
$$

if $s_{t}=1$, where * denotes that the information set includes the realized states. The unexpected monetary policy shocks in these two cases can then be defined as

$$
\begin{aligned}
\varepsilon_{0 t} & =\Delta m_{t} \\
& -\left[\begin{array}{l}
\mu_{0}+\Phi \\
\left(\Delta m_{t-1}-\left(\mu_{0}+\Delta \mu \pi_{01}\right)\right)+\Theta x_{t-1}
\end{array}\right] \sim N\left(0, \sigma_{0}^{2}\right) \\
\varepsilon_{1 t} & =\Delta m_{t} \\
& -\left[\begin{array}{l}
\mu_{0}+\Delta \mu+\Phi \\
\left(\Delta m_{t-1}-\left(\mu_{0}+\Delta \mu \pi_{11}\right)\right)+\Theta x_{t-1}
\end{array}\right] \sim N\left(0, \sigma_{1}^{2}\right) .
\end{aligned}
$$

The true information set, however, does not include the realized state, so we need to draw an inference on the regimes. To do this we use the estimates of the probabilities of being in each of the two regimes. Let $P\left(s_{t}=i \mid I_{t}\right)$ be the (estimated) probability conditional on information available at time $t$ that the state is equal to $i$ at time $t$ using the (modified) Hamilton filter. Assume also that state 0 is the state in which the variance of unanticipated monetary policy shocks is low. We can then define the two shocks in the following manner:

$$
\begin{aligned}
e_{t}^{S} & \equiv\left(\Delta m_{t}-\left[\mu_{0}+\Phi\left(\begin{array}{l}
\Delta m_{t-1}- \\
\left(\mu_{0}+\Delta \mu \pi_{01}\right)
\end{array}\right)+\Theta x_{t-1}\right]\right) \\
& \times P\left(s_{t}=0 \mid I_{t}\right)
\end{aligned}
$$

and

$$
\begin{aligned}
e_{t}^{B} & \equiv\left(\Delta m_{t}-\left[\mu_{0}+\Delta \mu+\Phi\left(\begin{array}{l}
\Delta m_{t-1}- \\
\left(\mu_{0}+\Delta \mu \pi_{11}\right)
\end{array}\right)+\Theta x_{t-1}\right]\right) \\
& \times P\left(s_{t}=1 \mid I_{t}\right) .
\end{aligned}
$$

Next, each of these two shocks can be divided into their positive and negative parts, which we denote by + (positive) and - (negative), using the same technique as in the previous section. Accordingly, we end up with four monetary policy shocks, $e_{t}=\left\{e_{t}^{B+}, e_{t}^{B-}, e_{t}^{S+}, e_{t}^{S-}\right\}$. This construction allows us 
to test for the presence of asymmetric effects using the following procedure. ${ }^{16}$

We estimate jointly the monetary policy equation (13) and the following version of the output equation ${ }^{17}$ :

$$
\begin{aligned}
\Delta y_{t} & =\psi Z_{t}+\beta^{B+} \Delta e_{t}^{B+}+\beta^{B-} \Delta e_{t}^{B-} \\
& +\beta^{S+} \Delta e_{t}^{S+}+\beta^{S-} \Delta e_{t}^{S-}+\xi_{t} .
\end{aligned}
$$

First we estimate equations (13) and (17), imposing that all the $\beta$ coefficients are equal to 0 - that is, that money has no real effects. We call this Case 0. Next, we estimate the system that allows the unanticipated monetary policy shocks to enter unrestricted. We call this Case 1. At this point one can look at the significance of each of the shocks as a check on signs of asymmetric effects; one can also check for monetary neutrality by using a likelihoodratio (LR) test (with four degrees of freedom) if it is tested against Case 0 .

The tests for asymmetries are carried out in a sequential manner using LR tests by imposing parameter restrictions on the coefficients on $\Delta e_{t}$. First we impose the following:

(18) Case 2: $H_{0}: \beta^{B+}=\beta^{B-}=\beta^{S+}=\beta^{S^{-}}$.

Asking whether Case 2 is a valid simplification of Case 1 is equivalent to testing for the absence of any asymmetry and can be performed as an LR test that is $\chi^{2}$-distributed with three degrees of freedom under the null. If these restrictions are rejected, the tests for the two versions of asymmetric effects are carried out by imposing a number of different parameter restrictions.

First, consider the case of testing for the asymmetry hypothesis that positive and negative monetary policy shocks have different effects; this can be tested in two steps. According to this hypothesis, it should not matter whether a given monetary policy shock is big or small. Hence, we impose the following:

(19) Case 3: $H_{0}: \beta^{B+}=\beta^{S+}$ and $\beta^{B-}=\beta^{S-}$.

Comparing Case 3 with Case 1 constitutes the first assessment of this hypothesis. It is further required that positive shocks are neutral. Hence, we impose the following:

\footnotetext{
${ }^{16}$ Alternatively, one can use a method of simulated moments to obtain estimates of the unexpected money growth.

${ }^{17}$ The models were estimated using a maximum-likelihood estimator for the joint system of equations.
}

(20) Case 4: $H_{0}: \beta^{B+}=\beta^{S+}=0$ and $\beta^{B-}=\beta^{S^{-}}$.

Comparing Case 4 with Case 3 is a way to assess whether positive shocks are neutral. If these tests are passed and the coefficient on the negative shocks is significantly positive, the data support the traditional Keynesian asymmetry hypothesis.

The other asymmetry hypothesis can be tested similarly. First we impose the following:

(21) Case 5: $H_{0}: \beta^{B+}=\beta^{B-}$ and $\beta^{S+}=\beta^{S^{-}}$.

Testing Case 5 against Case 1 constitutes the first part of the hypothesis. The second part imposes that big shocks are neutral:

(22) Case 6: $H_{0}: \beta^{B+}=\beta^{B-}=0$ and $\beta^{S+}=\beta^{S^{-}}$.

Again, we test this specification against Case 5 , and if the test is passed the hypothesis is backed by the data. A last case to consider is the hybrid version in which only small negative shocks have real effects. We can test the hybrid version in any of the sequences outlined above. This can be performed by imposing the following:

(23) Case 7: $H_{0}: \beta^{B+}=\beta^{B-}=\beta^{S+}=0$.

We test this against Case 1 because this case might not be nested within Case 4 or Case 6 if the null is correct. 18

\section{EMPIRICAL TESTS FOR THE UNITED STATES}

In this section, we empirically test for the different varieties of asymmetric effects of nominal demand on real activity discussed in the previous section. We look at two alternative sets of quarterly data for the United States. ${ }^{19}$ The first data set covers the period 1948-87 and the second data set covers the period 1960-95.

In both applications we use the empirical method described above, but the two applications differ in the measure of monetary policy that is used.

\footnotetext{
18 The main difference between our approach and other applications is the definition of big and small shocks. Demery (1993) makes the distinction by defining the former as those that are in a two-standard-error interval around 0 and the latter as those not belonging to this interval (i.e., as outliers). Caballero and Engel (1993) apply a similar strategy when testing for asymmetries in the price adjustments of firms in the face of nominal rigidities and changes in demand. This definition is not appropriate in light of our analysis in the previous section and may produce estimates of wrongly identified monetary policy shocks.

${ }^{19}$ The data are described in more detail in the appendix.
} 
For the first data set, we use the logarithm of M1 as the measure of monetary policy. When looking at the more recent data, we use the (negative of the) federal funds rate. The procedure we use depends on the time-series properties of the data in question, since we need to forecast the monetary policy process. Preliminary data analysis revealed that the logarithm of the money supply has a unit root, whereas the federal funds rate is a stationary process. Given this, for the federal funds rate we estimate equation (13) in levels using $-r^{f}$ as the measure of $\Delta m_{t}$. For the money-stock measure, we use the first difference of the logarithm to construct the onestep-ahead forecast error. Let $M_{t}$ be the money series that has a unit root-then the one-step-ahead forecast will be

$$
M_{t+1}^{e}=M_{t}+\hat{Y}(L) \Delta M_{t},
$$

where $\hat{Y}(L)$ is an estimator of $Y(L)$,

$$
\widehat{\Delta M}_{t}=\hat{Y}(L) \Delta M_{t-1} .
$$

This implies that the unanticipated money shock can be written as

$$
e_{t+1}=M_{t+1}-\left(M_{t}+\hat{Y}(L) \Delta M_{t}\right) .
$$

Note that the theoretical relationships that we want to consider are in "levels," whereas the empirical model is in "differences"; therefore, we consider relationships of the type expressed in equation (12) to preserve the theoretical structure of interest:

$$
\Delta y_{t}=\psi z_{t}+\beta\left(e_{t}-e_{t-1}\right)+\xi_{t} .
$$

Another issue to be addressed is the specification of the relationships for monetary policy and output. The money-supply process is specified as in Barro and Rush (1980), as in Mishkin (1982), or as an "optimal" money supply. ${ }^{20}$ The two specifications of the output equation have in common that $z_{t}$ includes a constant, lagged change in real output, $\varepsilon_{t}^{+}$ and $\varepsilon_{t}^{-}$; but the two specifications differ in whether the change in the T-bill rate is included or not.

In all of the above money-supply processes there are signs (i) of misspecification related to the

\footnotetext{
20 In the Barro-Rush specification, the vector of regressors $x_{t-1}$ includes a constant, the unemployment rate, and the contemporaneous real federal expenditures to normal expenditures. In the "modified Mishkin" specification, $x_{t-1}$ contains constant, lagged changes in money supply, lagged changes in the T-bill rate, and lagged values of the federal government's budget surplus. The "optimal" specification includes various elements of the above variables as well as lagged values of the changes in the monetary base.
}

existence of an outlier (at the first quarter of 1983, when the Volcker regime ended) in the moneysupply residuals and (ii) of heteroskedasticity of the money-supply residuals (details can be found in Ravn and Sola, 1996). For these reasons, we estimate (using a general-to-specific approach) an alternative moneysupply process that includes the first lag of M1 growth; the fourth- to the sixth-quarter lags of the (log of the) federal government's budget surplus; the first, fifth, and sixth lags of the log difference of the monetary base; the two-quarter lag of the unemployment rate; the second and the sixth lags of output growth; and the first, third, and fifth lags of the first difference of the T-bill rate. ${ }^{21,22}$ This relationship was identified by testing downward from a relationship that initially included six lags of all the variables.

In the second application we use the negative of the federal funds rate as the measure of monetary policy. We use the negative of the federal funds rate such that a positive shock to the monetary policy process can be interpreted as a loosening of monetary policy. In this application, the vector of regressors in the monetary policy relationship includes four lags of the (negative of the) federal funds rate, four lags of the log difference of GDP, four lags of the log difference of nonborrowed reserves, four lags of the log difference of total reserves, and four lags of the log difference of the implicit GDP deflator. ${ }^{23}$

For both sets of data we specified the output equation (17) such that it includes one lag of output growth, the first difference of the T-bill rate, and the lag of the first-differenced T-bill rate.

\section{Results for M1}

\section{Single-Equation Estimates of the Money}

Supply. We first turn to the results of single-equation estimates of the money-supply process with changes in regime. Figure 1 illustrates the first difference of the log of M1, and Table 1 reports

\footnotetext{
21 It also turns out that, once one corrects for the presence of the outlier the results on asymmetric effects are no longer valid. Specifically, one can in this case no longer reject a hypothesis that the positive and negative shocks have the same effect on output and that they are neutral. Details on results are given in Ravn and Sola (1996, Table 3).

22 Belongia (1996) documents another problem with the asymmetry result for the U.S. data. Belongia (1996) shows that if one uses a divisia index for the money stock, then one cannot reject the hypothesis that positive and negative money-supply shocks have symmetric effects.

${ }^{23}$ We also experimented with including the unemployment rate, but this variable did not affect the results. It should also be noted that we have not included the index of sensitive commodity prices that Christiano, Eichenbaum, and Evans (1996) introduce to address the "price puzzle." This issue is not important for our analysis.
} 


\section{Figure 1}

The Growth Rate of M1

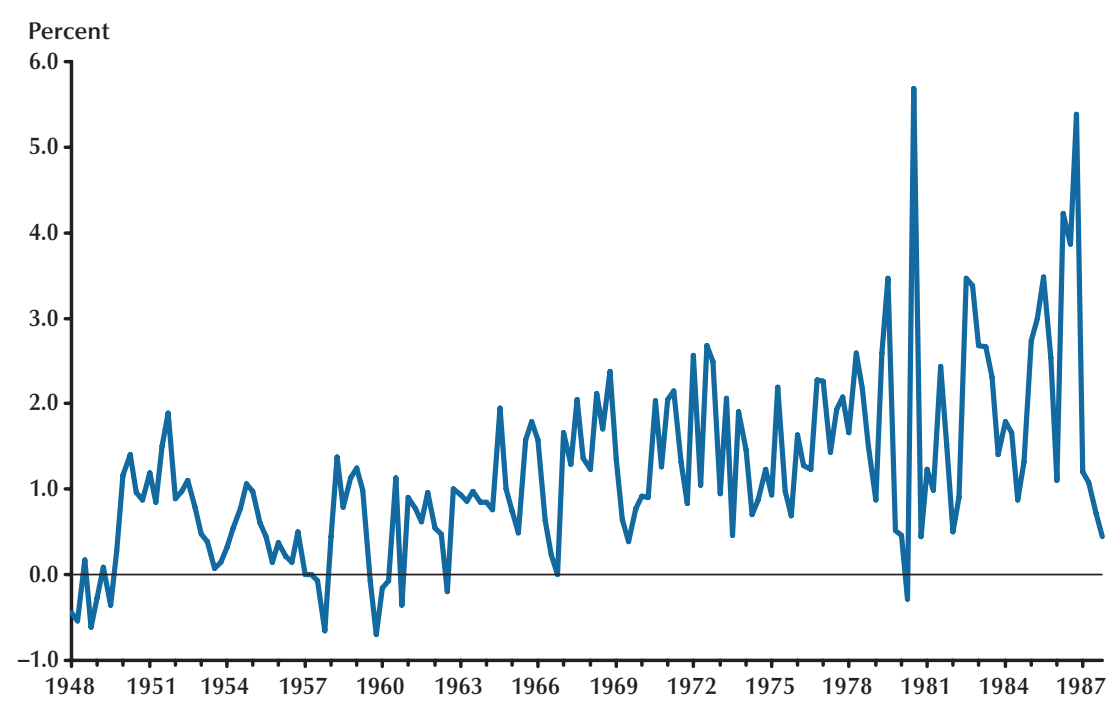

\section{Figure 2}

Filter Probabilities: Single Equation Results for M1

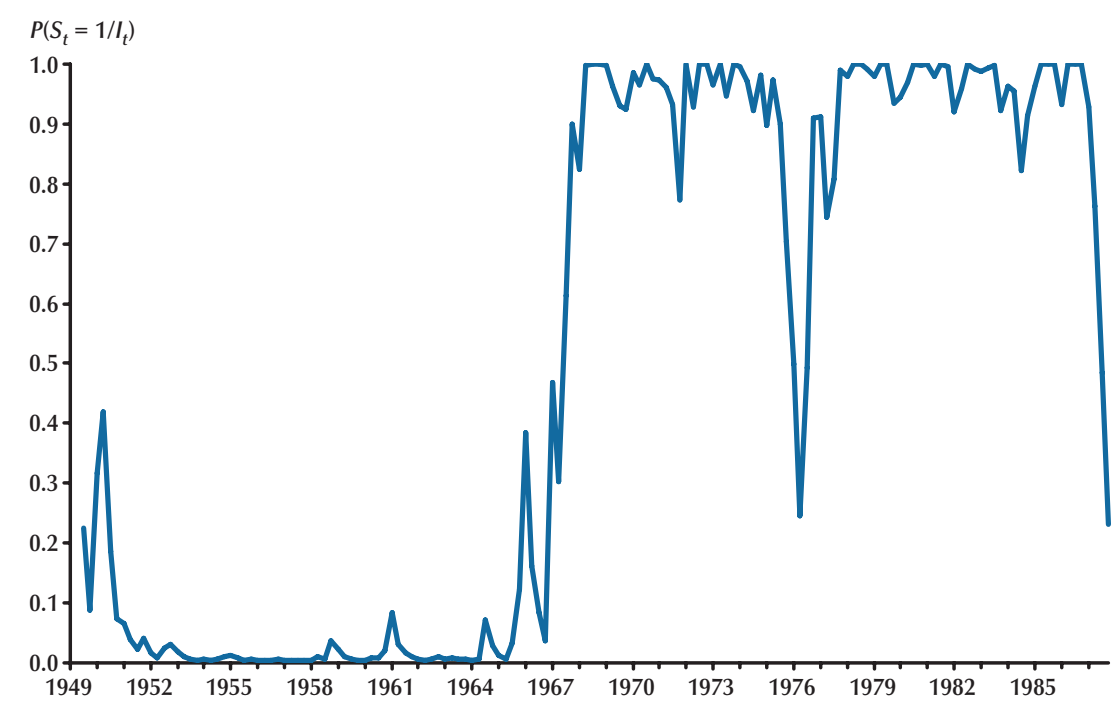

the results for the estimation of the money-supply process with changes in regime. We find that the changes in both the mean and the variance of the process are significant. The estimates suggest that there is a low-mean, low-variance regime where the mean is around 0.7 percent per quarter and the standard deviation around 0.4 percent and a highmean, high-variance regime where the mean is around 1.65 percent per quarter and the standard deviation around 0.8 . That is, the mean and standard deviation of the innovation in the "high" state (state 1) of money supply are roughly twice the corresponding numbers in the "low" state (state 0). Note also that both regimes are quite persistent, since the diagonal elements of the transition matrix are both in excess of 0.98 . 


\section{Table 1}

Money Supply with Changes in Regime: M1 Process, Single-Equation Results, 1948:Q1-1987:Q4

\begin{tabular}{|c|c|c|c|c|}
\hline Variable & Estimate & Variable & Estimate & Test statistic \\
\hline$\Delta m 1_{t-1}$ & $\begin{array}{c}0.257 \\
(0.072)\end{array}$ & $\mu_{0}$ & $\begin{array}{c}0.726 \\
(0.131)\end{array}$ & $\begin{array}{c}Q(1)=0.295 \\
{[0.587]}\end{array}$ \\
\hline$u_{t-2}$ & $\begin{array}{c}0.403 \\
(0.189)\end{array}$ & $\Delta \mu$ & $\begin{array}{c}0.934 \\
(0.235)\end{array}$ & $\begin{array}{c}Q(10)=9.521 \\
{[0.709]}\end{array}$ \\
\hline$f s_{t-4}$ & $\begin{array}{l}-1.160 \\
(0.608)\end{array}$ & $\sigma_{0}$ & $\begin{array}{c}0.417 \\
(0.041)\end{array}$ & $\begin{array}{c}Q Q(1)=2.264 \\
{[0.132]}\end{array}$ \\
\hline$f s_{t-5}$ & $\begin{array}{c}2.254 \\
(0.843)\end{array}$ & $\Delta \sigma$ & $\begin{array}{c}0.368 \\
(0.077)\end{array}$ & $\begin{array}{c}Q Q(10)=16.120 \\
{[0.096]}\end{array}$ \\
\hline$f s_{t-6}$ & $\begin{array}{l}-1.234 \\
(0.528)\end{array}$ & $\pi_{00}$ & $\begin{array}{c}0.985 \\
(0.015)\end{array}$ & \\
\hline$\Delta b_{t-1}$ & $\begin{array}{c}0.078 \\
(0.092)\end{array}$ & $\pi_{11}$ & $\begin{array}{c}0.989 \\
(0.013)\end{array}$ & \\
\hline$\Delta b_{t-5}$ & $\begin{array}{c}0.141 \\
(0.079)\end{array}$ & & & \\
\hline$\Delta b_{t-6}$ & $\begin{array}{l}-0.180 \\
(0.089)\end{array}$ & & & \\
\hline$\Delta y_{t-2}$ & $\begin{array}{c}0.144 \\
(0.042)\end{array}$ & & & \\
\hline$\Delta y_{t-6}$ & $\begin{array}{c}0.115 \\
(0.048)\end{array}$ & & & \\
\hline$\Delta t b r_{t-1}$ & $\begin{array}{l}-0.405 \\
(0.054)\end{array}$ & & & \\
\hline$\Delta t b r_{t-3}$ & $\begin{array}{l}-0.199 \\
(0.058)\end{array}$ & & & \\
\hline$\Delta t b r_{t-5}$ & $\begin{array}{l}-0.144 \\
(0.056)\end{array}$ & & & \\
\hline
\end{tabular}

NOTE: $\Delta m 1$ is the log difference of $M 1 ; u$ is the unemployment rate; $f$ is the log of the federal government's budget surplus; $\Delta b$ is the log difference of the monetary base; $\Delta y$ is the log difference of GNP; and $\Delta t b r$ is the difference of the T-bill rate. $Q(x)(Q Q(x))$ is the Box-Pierce test for autocorrelation in the standardized residuals (squared standardized residuals) of order $x$. Numbers in parentheses are standard errors; numbers in brackets are probabilities.

Figure 2 illustrates the estimated probabilities of being in regime 1 , the regime in which the mean and the variance are both high. The filter divides the sample very clearly into the two regimes, and the estimates imply that money growth and the variance of money growth were low from the start of the sample until 1967. From 1967 to 1987:Q4, the probability of being in the regime with high mean and high variance is practically equal to 1 , with the exception of the last three quarters of 1976 and the final three observations. It should also be noted that there are no signs of specification errors in the regression residuals.
Tests for Asymmetric Effects. We first estimate Case 0, that is, the output equation, without money entering into it. This is reported in the first column of Table 2 . We see that the output equation is relatively well estimated, with no signs of misspecification in the errors. Next, we estimate the system, letting each of the money-shock components enter unrestricted (Case 1). None of the four money-supply shocks are significant individually, but the LR test implies that the four shocks are significant jointly. There is no clear pattern that leads one to suspect the presence of asymmetries, but to test this more formally we use the procedure outlined above. 


\section{Table 2}

\section{Output Equation ML Estimates: M1 Measure, 1948:Q1-1987:Q4}

\begin{tabular}{|c|c|c|c|c|c|c|c|c|}
\hline Variable & Case 0 & Case 1 & Case 2 & Case 3 & Case 4 & Case 5 & Case 6 & Case 7 \\
\hline Constant & $\begin{array}{c}0.540 \\
(0.098)\end{array}$ & $\begin{array}{c}0.502 \\
(0.098)\end{array}$ & $\begin{array}{c}0.520 \\
(0.097)\end{array}$ & $\begin{array}{c}0.502 \\
(0.098)\end{array}$ & $\begin{array}{c}0.520 \\
(0.097)\end{array}$ & $\begin{array}{c}0.507 \\
(0.098)\end{array}$ & $\begin{array}{c}0.502 \\
(0.096)\end{array}$ & $\begin{array}{c}0.533 \\
(0.098)\end{array}$ \\
\hline$\Delta y_{t-1}$ & $\begin{array}{c}0.329 \\
(0.075)\end{array}$ & $\begin{array}{c}0.370 \\
(0.076)\end{array}$ & $\begin{array}{c}0.353 \\
(0.074)\end{array}$ & $\begin{array}{c}0.369 \\
(0.075)\end{array}$ & $\begin{array}{c}0.355 \\
(0.075)\end{array}$ & $\begin{array}{c}0.371 \\
(0.055)\end{array}$ & $\begin{array}{c}0.376 \\
(0.075)\end{array}$ & $\begin{array}{c}0.337 \\
(0.075)\end{array}$ \\
\hline$\Delta t b r_{t}$ & $\begin{array}{c}0.272 \\
(0.067)\end{array}$ & $\begin{array}{c}0.278 \\
(0.067)\end{array}$ & $\begin{array}{c}0.284 \\
(0.067)\end{array}$ & $\begin{array}{c}0.278 \\
(0.067)\end{array}$ & $\begin{array}{c}0.277 \\
(0.067)\end{array}$ & $\begin{array}{c}0.285 \\
(0.067)\end{array}$ & $\begin{array}{c}0.285 \\
(0.067)\end{array}$ & $\begin{array}{c}0.272 \\
(0.068)\end{array}$ \\
\hline$\Delta t b r_{t-1}$ & $\begin{array}{c}0.081 \\
(0.071)\end{array}$ & $\begin{array}{c}0.051 \\
(0.073)\end{array}$ & $\begin{array}{c}0.071 \\
(0.071)\end{array}$ & $\begin{array}{c}0.052 \\
(0.073)\end{array}$ & $\begin{array}{c}0.057 \\
(0.071)\end{array}$ & $\begin{array}{c}0.070 \\
(0.071)\end{array}$ & $\begin{array}{c}0.071 \\
(0.070)\end{array}$ & $\begin{array}{c}0.079 \\
(0.071)\end{array}$ \\
\hline$\Delta e_{t}^{S+}$ & - & $\begin{array}{c}0.071 \\
(0.391)\end{array}$ & $\begin{array}{c}0.184 \\
(0.083)\end{array}$ & $\begin{array}{c}0.025 \\
(0.160)\end{array}$ & - & $\begin{array}{c}0.395 \\
(0.219)\end{array}$ & $\begin{array}{c}0.448 \\
(0.174)\end{array}$ & - \\
\hline$\Delta e_{t}^{S-}$ & - & $\begin{array}{c}0.370 \\
(0.386)\end{array}$ & $\begin{array}{c}0.184 \\
(0.083)\end{array}$ & $\begin{array}{c}0.415 \\
(0.220)\end{array}$ & $\begin{array}{c}0.363 \\
(0.166)\end{array}$ & $\begin{array}{c}0.395 \\
(0.219)\end{array}$ & $\begin{array}{c}0.448 \\
(0.174)\end{array}$ & $\begin{array}{c}0.335 \\
(0.377)\end{array}$ \\
\hline$\Delta e_{t}^{B+}$ & - & $\begin{array}{c}0.003 \\
(0.106)\end{array}$ & $\begin{array}{c}0.184 \\
(0.083)\end{array}$ & $\begin{array}{c}0.025 \\
(0.160)\end{array}$ & - & $\begin{array}{c}0.075 \\
(0.178)\end{array}$ & - & - \\
\hline$\Delta \mathrm{e}_{t}^{B-}$ & - & $\begin{array}{c}0.432 \\
(0.240)\end{array}$ & $\begin{array}{c}0.184 \\
(0.083)\end{array}$ & $\begin{array}{c}0.415 \\
(0.220)\end{array}$ & $\begin{array}{c}0.363 \\
(0.166)\end{array}$ & $\begin{array}{c}0.075 \\
(0.178)\end{array}$ & - & - \\
\hline$\sigma_{Y}$ & 0.972 & 0.950 & 0.956 & 0.950 & 0.954 & 0.950 & 0.947 & 0.969 \\
\hline$Q(1)$ & $\begin{array}{c}0.174 \\
{[0.677]}\end{array}$ & $\begin{array}{c}0.371 \\
{[0.543]}\end{array}$ & $\begin{array}{c}0.169 \\
{[0.680]}\end{array}$ & $\begin{array}{c}0.392 \\
{[0.531]}\end{array}$ & $\begin{array}{c}0.232 \\
{[0.630]}\end{array}$ & $\begin{array}{c}0.186 \\
{[0.666]}\end{array}$ & $\begin{array}{c}0.191 \\
{[0.662]}\end{array}$ & $\begin{array}{c}0.269 \\
{[0.604]}\end{array}$ \\
\hline$Q(10)$ & $\begin{array}{c}8.474 \\
{[0.583]}\end{array}$ & $\begin{array}{c}7.652 \\
{[0.663]}\end{array}$ & $\begin{array}{c}7.957 \\
{[0.633]}\end{array}$ & $\begin{array}{c}8.050 \\
{[0.624]}\end{array}$ & $\begin{array}{c}8.408 \\
{[0.589]}\end{array}$ & $\begin{array}{c}7.487 \\
{[0.679]}\end{array}$ & $\begin{array}{c}8.997 \\
{[0.532]}\end{array}$ & $\begin{array}{c}9.518 \\
{[0.484]}\end{array}$ \\
\hline$Q Q(1)$ & $\begin{array}{c}2.165 \\
{[0.141]}\end{array}$ & $\begin{array}{c}4.964 \\
{[0.026]}\end{array}$ & $\begin{array}{c}3.166 \\
{[0.075]}\end{array}$ & $\begin{array}{c}4.991 \\
{[0.026]}\end{array}$ & $\begin{array}{c}4.312 \\
{[0.038]}\end{array}$ & $\begin{array}{c}3.441 \\
{[0.064]}\end{array}$ & $\begin{array}{c}2.982 \\
{[0.084]}\end{array}$ & $\begin{array}{c}2.932 \\
{[0.087]}\end{array}$ \\
\hline$Q Q(10)$ & $\begin{array}{c}7.306 \\
{[0.696]}\end{array}$ & $\begin{array}{c}12.575 \\
{[0.248]}\end{array}$ & $\begin{array}{c}9.958 \\
{[0.444]}\end{array}$ & $\begin{array}{c}12.427 \\
{[0.258]}\end{array}$ & $\begin{array}{c}11.246 \\
{[0.339]}\end{array}$ & $\begin{array}{c}11.114 \\
{[0.349]}\end{array}$ & $\begin{array}{c}10.867 \\
{[0.368]}\end{array}$ & $\begin{array}{c}8.264 \\
{[0.603]}\end{array}$ \\
\hline $\begin{array}{l}\text { Log likelihood } \\
\text { LR test }\end{array}$ & -358.71 & $\begin{array}{c}-352.78 \\
11.94^{0)} \\
{[0.018]}\end{array}$ & $\begin{array}{c}-356.32 \\
7.08^{1)} \\
{[0.069]}\end{array}$ & $\begin{array}{c}-352.79 \\
0.03^{2)} \\
{[0.983]}\end{array}$ & $\begin{array}{c}-356.42 \\
7.25^{3)} \\
{[0.007]}\end{array}$ & $\begin{array}{c}-356.00 \\
6.44^{4)} \\
{[0.040]}\end{array}$ & $\begin{array}{c}-356.05 \\
0.098^{5)} \\
{[75.42]}\end{array}$ & $\begin{array}{c}-358.33 \\
11.10^{6)} \\
{[0.011]}\end{array}$ \\
\hline
\end{tabular}

NOTE: See note to Table 1. The monetary shocks refer to unanticipated shocks. We do not report the estimates of the money-supply equations (which are jointly estimated by $\mathrm{ML}$ ), but they are available upon request. 0 ) $L R$ test of Case 0 vs. Case $1 ; 1$ ) $L R$ test of Case 2 vs. Case 1 ; 2) $L R$ test of Case 3 vs. Case 1;3) $L R$ test of Case 4 vs. Case 3; 4) $L R$ test of Case 5 vs. Case $1 ; 5) L R$ test of Case 6 vs. Case 5 ; 6) $L R$ test of Case 7 vs. Case 6.

First we impose the restrictions based on Case 2 , that is, absence of asymmetries. We obtain a $p$ value of 6.94 percent for this hypothesis, implying that there is no strong evidence in favor of asymmetric effects once one allows all the coefficients to enter unrestricted in the alternative hypothesis. Notice also that, once these restrictions are imposed, we obtain significant coefficients on the unanticipated shocks to $M_{1}$. However, we still test for asymmetries and first look at the traditional Keynesian hypothesis; that is, we impose the restrictions of
Case 3. These restrictions imply that big and small shocks enter with the same coefficients. The parameter estimates now imply that negative shocks enter with a coefficient that is much larger than that of positive shocks. Furthermore, the LR test indicates that the restrictions cannot be rejected at any conventional significance level (in spite of the coefficients being insignificant individually).

When we impose that the positive shocks are neutral, we find that the negative shocks become significant; but, when tested against Case 3, the 
restrictions of Case 4 are strongly rejected. It should be noted, however, that the positive shocks have very small effects on output. Thus, even though we formally reject that these shocks are neutral, their quantitative effects appear limited.

The other alternative to be tested is whether big and small money-supply shocks have asymmetric effects on output. First we impose the restrictions under Case 5 (i.e., that it is irrelevant whether the shocks are positive or negative). We find that the probability value of the LR test of this hypothesis is 4 percent, which implies that we would reject the null hypothesis at the 5 percent level. One might be tempted to continue with the hypothesis, given the marginal rejection. In that case one would not be able to reject that big shocks are neutral, thus finding evidence in favor of the menu-cost type of asymmetry. However, the likelihood of Case 5 is much worse than the competing likelihood of Case 3: Thus, in this respect, Case 3 appears to be the better specification. Finally, we need to look at Case 7 , the case based on the hybrid asymmetry. This case is rejected regardless of which alternative it is tested against.

In conclusion, the data give some support to the idea that negative monetary policy shocks have larger real effects than positive monetary policy shocks. However, at the same time, we cannot formally reject that all types of shocks have identical effects on output - that is, that monetary policy has symmetric effects. And, regardless of this, we find very small monetary policy effects. Thus, while the evidence does not directly contradict previous evidence, the results do not strongly support the traditional Keynesian asymmetry.

\section{Results for the Federal Funds Rate}

As discussed previously, there are reasons to expect that the results above might be hampered by the structural instability of M1 demand. It has previously been shown that M1 demand has been relatively unstable in the 1980s and the 1990s. This implies that the shocks identified above, as a "monetary policy" shock, may well indeed be a mixture of money-demand and money-supply shocks. (See, e.g., Baba, Hendry, and Starr, 1992, or Stock and Watson, 1993, for a discussion.) It has also been claimed that the federal funds rate may be a better indicator of monetary policy. ${ }^{24}$ The reason is that much of the Federal Reserve's intervention takes place in the form of changes in nonborrowed

\footnotetext{
${ }^{24}$ Hamilton (1996) provides an excellent discussion and analysis of the federal funds daily market.
}

reserves, which affect the interest rate in the reserve market, that is, the federal funds rate. For these reasons we now take up the question of asymmetric effects using the federal funds rate rather than M1. To facilitate an easy comparison with the analysis for M1, we will transform the federal funds rate and measure it by the negative of the federal funds rate such that positive shocks indicate a loosening of monetary policy. The federal funds rate is illustrated graphically in Figure 3. One notices immediately the volatile behavior of the federal funds rate in the early 1980s.

Single-Equation Estimates. We start by looking at the results of single-equation estimates of the federal funds rate process using the regime-switching technique. The federal funds rate process includes four lags of the following five variables: (i) the federal funds rate, (ii) the log-difference of GDP, (iii) the logdifference of the implicit GDP deflator, (iv) the logdifference of non-borrowed reserves, and (v) the log-difference of total reserves. 25

Table 3 reports the single-equation results of the estimation of the process for the federal funds rate. As for M1, we find that there are clear signs of changes in regime. We find a low-mean, low-variance regime and a high-mean, high-variance regime. In the low regime the mean of the federal funds rate is estimated to be around 6.4 percent and the standard deviation to be 0.42 percent. In the high regime, the mean is estimated to be around 8.4 percent and the standard deviation to be 2.2 percent. Evidently, it is the change in the variance that dominates the change in regime in this process. Furthermore, from the estimates of the Markov transition probabilities, one can see that the low-mean, low-variance regime is much more persistent than the high-mean, highvariance regime. The probabilities imply that the expected duration of the low-mean, low-variance regime is close to 15 years, while the expected duration of the high-mean, high-variance regime is exactly equal to 2 years.

Figure 4 illustrates the estimated probabilities of each of the two regimes. The regime with low funds rates and a low variance of the innovations is estimated to dominate most of the sample period. There are two periods in which the regime with high funds rates and high volatility takes over. The first period is the period immediately after the first oil-

\footnotetext{
25 The results are robust to changes in the federal funds rate process. We experimented with the inclusion of the unemployment rate, with using the CPI rather than the GDP deflator, and with using industrial production rather than GDP. We also experimented with alternative lag lengths and got the same results as those reported here.
} 


\section{Figure 3}

\section{Federal Funds Rate}

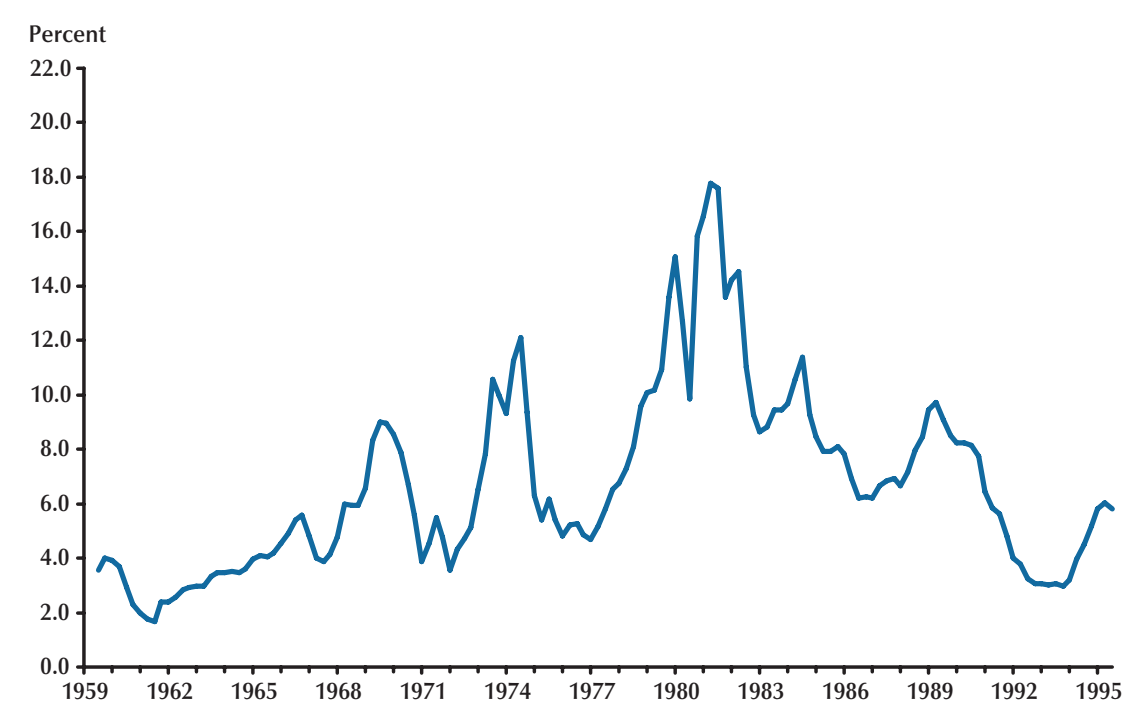

\section{Figure 4}

Filter Probabilities: Single-Equation Results for the Funds Rate

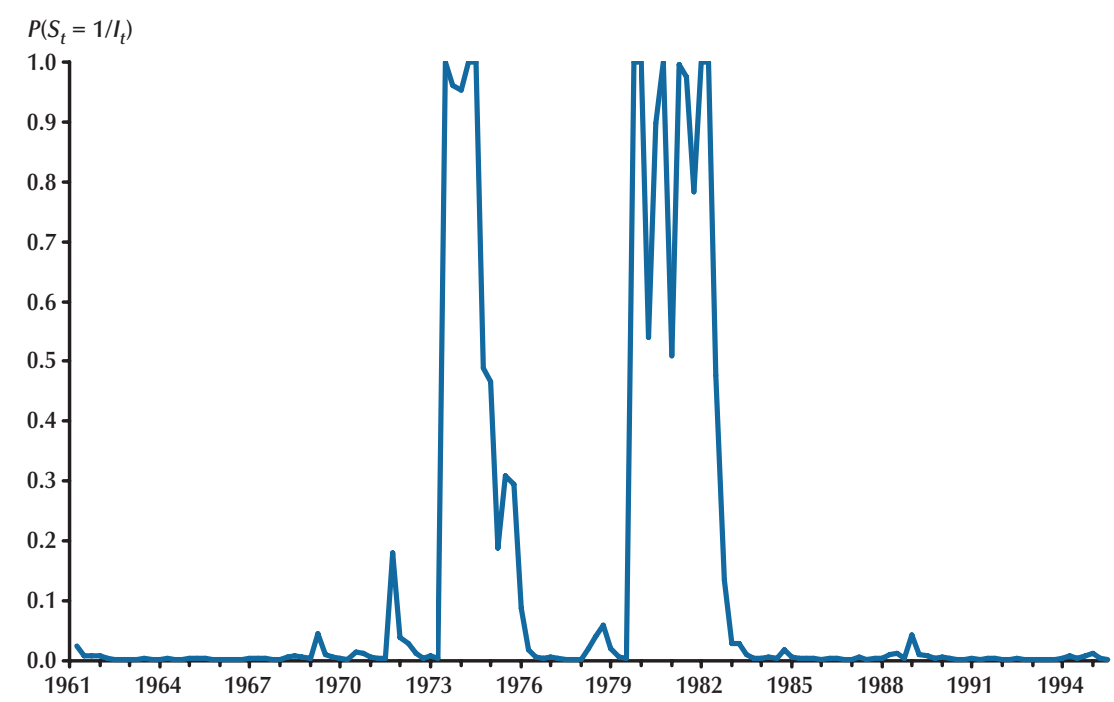

price shock, 1973:Q3-1975:Q4. The second period is, not surprisingly, the Volcker period, 1979:Q3 1982:Q3. (One might also include 1982:Q4 in this regime, but our estimates imply that the probability of the high regime is 13.4 percent for this observation.) These results seem much more sensible than the dating of regimes in the application using M1.

Tests for Asymmetric Effects Using the
Federal Funds Rate. In this application we use GDP as the measure rather than gross national product, which is used for the analysis with the M1 data. The results are reported in Table 4.

In the first column we report the results for the output equation that excludes the monetary policy shocks; in the second column, we report the results when each of the four shocks enter unrestricted. 


\section{Table 3}

Money Supply with Changes in Regime: Federal Funds Rate Process Single-Equation Results, 1959:Q3-1995:Q3

\begin{tabular}{|c|c|c|c|c|}
\hline Variable & Estimate & Variable & Estimate & Test statistic \\
\hline$-f f_{t-1}$ & $\begin{array}{c}1.226 \\
(0.108)\end{array}$ & $\Delta t r_{t-1}$ & $\begin{array}{l}-0.178 \\
(0.044)\end{array}$ & $\begin{array}{c}Q(1)=0.002 \\
{[0.968]}\end{array}$ \\
\hline$-f f_{t-2}$ & $\begin{array}{l}-0.283 \\
(0.180)\end{array}$ & $\Delta t r_{t-2}$ & $\begin{array}{c}0.147 \\
(0.053)\end{array}$ & $\begin{array}{c}Q(10)=7.612 \\
{[0.667]}\end{array}$ \\
\hline$-f f_{t-3}$ & $\begin{array}{c}0.049 \\
(0.163)\end{array}$ & $\Delta t r_{t-3}$ & $\begin{array}{l}-0.011 \\
(0.059)\end{array}$ & $\begin{array}{c}Q Q(1)=0.305 \\
{[0.581]}\end{array}$ \\
\hline$-f f_{t-4}$ & $\begin{array}{l}-0.052 \\
(0.093)\end{array}$ & $\Delta t r_{t-4}$ & $\begin{array}{l}-0.024 \\
(0.046)\end{array}$ & $\begin{array}{c}Q Q(10)=7.378 \\
{[0.689]}\end{array}$ \\
\hline$\Delta n b r_{t-1}$ & $\begin{array}{c}0.145 \\
(0.038)\end{array}$ & & & \\
\hline$\Delta n b r_{t-2}$ & $\begin{array}{l}-0.113 \\
(0.043)\end{array}$ & $\mu_{0}$ & $\begin{array}{l}-6.362 \\
(0.675)\end{array}$ & \\
\hline$\Delta n b r_{t-3}$ & $\begin{array}{l}-0.041 \\
(0.045)\end{array}$ & $\Delta \mu$ & $\begin{array}{l}-2.031 \\
(0.486)\end{array}$ & \\
\hline$\Delta n b r_{t-4}$ & $\begin{array}{c}0.047 \\
(0.037)\end{array}$ & $\sigma_{0}$ & $\begin{array}{c}0.418 \\
(0.027)\end{array}$ & \\
\hline$\Delta y_{t-1}$ & $\begin{array}{l}-0.173 \\
(0.057)\end{array}$ & $\Delta \sigma$ & $\begin{array}{l}1.760 \\
(0.390)\end{array}$ & \\
\hline$\Delta y_{t-2}$ & $\begin{array}{l}-0.053 \\
(0.055)\end{array}$ & $\pi_{00}$ & $\begin{array}{c}0.875 \\
(0.080)\end{array}$ & \\
\hline$\Delta y_{t-3}$ & $\begin{array}{l}-0.069 \\
(0.054)\end{array}$ & $\pi_{11}$ & $\begin{array}{c}0.984 \\
(0.011)\end{array}$ & \\
\hline$\Delta y_{t-4}$ & $\begin{array}{c}0.021 \\
(0.051)\end{array}$ & & & \\
\hline$\Delta p_{t-1}$ & $\begin{array}{l}-0.377 \\
(0.172)\end{array}$ & & & \\
\hline$\Delta p_{t-2}$ & $\begin{array}{l}-0.285 \\
(0.162)\end{array}$ & & & \\
\hline$\Delta p_{t-3}$ & $\begin{array}{c}0.217 \\
(0.168)\end{array}$ & & & \\
\hline$\Delta p_{t-4}$ & $\begin{array}{c}0.207 \\
(0.168)\end{array}$ & & & \\
\hline
\end{tabular}

NOTE: - $f f$ is the negative of the federal funds rate; $\Delta n b r$ is the log difference of non-borrowed reserves; $\Delta y$ is the log difference of GDP; $\Delta p$ is the log difference of the implicit GDP deflator; and $\Delta t r$ is the log difference of total reserves.

For this specification, only the big negative shock enters significantly and the other components enter with negative coefficients, although they are insignificantly different from 0 . When tested against Case 0 , we strongly reject that money is neutral. From this perspective, there are signs of asymmetries, but the negative point estimates on some of the shocks seem slightly puzzling. In column 3 we impose that all four shocks enter with identical coefficients, and, again, the LR test strongly rejects this specification. Thus, we proceed to test for either of the two asymmetry hypotheses.

First we impose the parameter restrictions for Case 3. These restrictions have a probability value of just above 1 percent and are thus rejected. Given this, we proceed to Case 5 , which constitutes the first 


\section{Table 4}

\section{Output Equation ML Estimates: Federal Funds Rate Measure, 1948:Q1-1987:Q4}

\begin{tabular}{|c|c|c|c|c|c|c|c|c|}
\hline Variable & Case 0 & Case 1 & Case 2 & Case 3 & Case 4 & Case 5 & Case 6 & Case 7 \\
\hline Constant & $\begin{array}{c}0.582 \\
(0.097)\end{array}$ & $\begin{array}{c}0.544 \\
(0.114)\end{array}$ & $\begin{array}{c}0.581 \\
(0.111)\end{array}$ & $\begin{array}{c}0.587 \\
(0.119)\end{array}$ & $\begin{array}{c}0.595 \\
(0.097)\end{array}$ & $\begin{array}{c}0.571 \\
(0.095)\end{array}$ & $\begin{array}{c}0.590 \\
(0.097)\end{array}$ & $\begin{array}{c}0.569 \\
(0.095)\end{array}$ \\
\hline$\Delta y_{t-1}$ & $\begin{array}{c}0.253 \\
(0.081)\end{array}$ & $\begin{array}{c}0.301 \\
(0.098)\end{array}$ & $\begin{array}{c}0.255 \\
(0.096)\end{array}$ & $\begin{array}{c}0.246 \\
(0.098)\end{array}$ & $\begin{array}{c}0.246 \\
(0.081)\end{array}$ & $\begin{array}{c}0.276 \\
(0.081)\end{array}$ & $\begin{array}{c}0.252 \\
(0.081)\end{array}$ & $\begin{array}{c}0.279 \\
(0.080)\end{array}$ \\
\hline$\Delta t b r_{t}$ & $\begin{array}{c}0.002 \\
(0.001)\end{array}$ & $\begin{array}{c}0.002 \\
(0.001)\end{array}$ & $\begin{array}{c}0.002 \\
(0.001)\end{array}$ & $\begin{array}{c}0.003 \\
(0.001)\end{array}$ & $\begin{array}{c}0.003 \\
(0.001)\end{array}$ & $\begin{array}{c}0.003 \\
(0.001)\end{array}$ & $\begin{array}{c}0.002 \\
(0.001)\end{array}$ & $\begin{array}{c}0.003 \\
(0.001)\end{array}$ \\
\hline$\Delta t b r_{t-1}$ & $\begin{array}{c}0.001 \\
(0.001)\end{array}$ & $\begin{array}{c}0.001 \\
(0.001)\end{array}$ & $\begin{array}{c}0.001 \\
(0.001)\end{array}$ & $\begin{array}{c}0.001 \\
(0.001)\end{array}$ & $\begin{array}{c}0.001 \\
(0.0001)\end{array}$ & $\begin{array}{c}0.000 \\
(0.001)\end{array}$ & $\begin{array}{c}0.001 \\
(0.001)\end{array}$ & $\begin{array}{c}0.001 \\
(0.001)\end{array}$ \\
\hline$\Delta e_{t}^{S+}$ & - & $\begin{array}{l}-0.304 \\
(0.295)\end{array}$ & $\begin{array}{l}-0.006 \\
(1.413)\end{array}$ & $\begin{array}{c}0.000 \\
(0.237)\end{array}$ & - & $\begin{array}{c}0.000 \\
(0.082)\end{array}$ & $\begin{array}{c}0.000 \\
(0.102)\end{array}$ & - \\
\hline$\Delta e_{t}^{S-}$ & - & $\begin{array}{l}-0.086 \\
(0.145)\end{array}$ & $\begin{array}{l}-0.006 \\
(1.413)\end{array}$ & $\begin{array}{c}0.068 \\
(0.113)\end{array}$ & $\begin{array}{c}0.067 \\
(0.081)\end{array}$ & $\begin{array}{c}0.000 \\
(0.082)\end{array}$ & $\begin{array}{c}0.000 \\
(0.102)\end{array}$ & $\begin{array}{c}0.460 \\
(0.213)\end{array}$ \\
\hline$\Delta e_{t}^{B+}$ & - & $\begin{array}{l}-0.304 \\
(0.323)\end{array}$ & $\begin{array}{l}-0.006 \\
(1.413)\end{array}$ & $\begin{array}{c}0.000 \\
(0.237)\end{array}$ & - & $\begin{array}{c}0.246 \\
(0.120)\end{array}$ & - & - \\
\hline$\Delta e_{t}^{B-}$ & - & $\begin{array}{c}0.694 \\
(0.289)\end{array}$ & $\begin{array}{l}-0.006 \\
(1.413)\end{array}$ & $\begin{array}{c}0.068 \\
(0.113)\end{array}$ & $\begin{array}{c}0.067 \\
(0.081)\end{array}$ & $\begin{array}{c}0.246 \\
(0.120)\end{array}$ & - & - \\
\hline$\sigma_{Y}$ & 0.850 & 0.813 & 0.850 & 0.847 & 0.849 & 0.829 & 0.851 & 0.825 \\
\hline$Q(1)$ & $\begin{array}{c}0.000 \\
{[0.999]}\end{array}$ & $\begin{array}{c}0.001 \\
{[0.977]}\end{array}$ & $\begin{array}{c}0.001 \\
{[0.978]}\end{array}$ & $\begin{array}{c}0.044 \\
{[0.834]}\end{array}$ & $\begin{array}{c}0.048 \\
{[0.827]}\end{array}$ & $\begin{array}{c}0.064 \\
{[0.800]}\end{array}$ & $\begin{array}{c}0.000 \\
{[0.990]}\end{array}$ & $\begin{array}{c}0.002 \\
{[0.968]}\end{array}$ \\
\hline$Q(10)$ & $\begin{array}{c}8.747 \\
{[0.556]}\end{array}$ & $\begin{array}{c}7.226 \\
{[0.704]}\end{array}$ & $\begin{array}{c}8.857 \\
{[0.546]}\end{array}$ & $\begin{array}{c}7.662 \\
{[0.662]}\end{array}$ & $\begin{array}{c}7.700 \\
{[0.658]}\end{array}$ & $\begin{array}{c}7.306 \\
{[0.696]}\end{array}$ & $\begin{array}{c}8.762 \\
{[0.555]}\end{array}$ & $\begin{array}{c}7.235 \\
{[0.703]}\end{array}$ \\
\hline$Q Q(1)$ & $\begin{array}{c}0.384 \\
{[0.536]}\end{array}$ & $\begin{array}{c}0.346 \\
{[0.556]}\end{array}$ & $\begin{array}{c}0.397 \\
{[0.529]}\end{array}$ & $\begin{array}{c}0.194 \\
{[0.660]}\end{array}$ & $\begin{array}{c}0.215 \\
{[0.643]}\end{array}$ & $\begin{array}{c}0.519 \\
{[0.471]}\end{array}$ & $\begin{array}{c}0.406 \\
{[0.524]}\end{array}$ & $\begin{array}{c}0.377 \\
{[0.539]}\end{array}$ \\
\hline$Q Q(10)$ & $\begin{array}{c}10.25 \\
{[0.419]}\end{array}$ & $\begin{array}{c}12.41 \\
{[0.259]}\end{array}$ & $\begin{array}{c}10.34 \\
{[0.411]}\end{array}$ & $\begin{array}{c}9.950 \\
{[0.445]}\end{array}$ & $\begin{array}{c}10.047 \\
{[0.436]}\end{array}$ & $\begin{array}{c}12.136 \\
{[0.276]}\end{array}$ & $\begin{array}{c}10.325 \\
{[0.413]}\end{array}$ & $\begin{array}{c}12.603 \\
{[0.247]}\end{array}$ \\
\hline $\begin{array}{l}\text { Log likelihood } \\
\text { LR test }\end{array}$ & -300.72 & $\begin{array}{c}-285.48 \\
30.5^{0)} \\
{[0.000]}\end{array}$ & $\begin{array}{c}-300.71 \\
30.5^{1)} \\
{[0.000]}\end{array}$ & $\begin{array}{c}-291.17 \\
11.4^{2)} \\
{[0.003]}\end{array}$ & $\begin{array}{c}-292.86 \\
3.39^{3)} \\
{[0.066]}\end{array}$ & $\begin{array}{c}-288.99 \\
7.01^{4)} \\
{[0.030]}\end{array}$ & $\begin{array}{c}-293.20 \\
8.43^{5)} \\
{[0.004]}\end{array}$ & $\begin{array}{c}-288.34 \\
5.71^{6)} \\
{[0.127]}\end{array}$ \\
\hline
\end{tabular}

NOTE: See note to Table 1.0$) L R$ test of Case 0 vs. Case $1 ; 1) L R$ test of Case 2 vs. Case $1 ; 2) L R$ test of Case 3 vs. Case 1 ; 3 ) $L R$ test of Case 4 vs. Case 3 ; 4) $L R$ test of Case 5 vs. Case 1 ; 5) $L R$ test of Case 6 vs. Case 5 ; 6$) L R$ test of Case 7 vs. Case 1.

step in testing for the menu-cost type asymmetry. These restrictions are (marginally) rejected since the probability value of the LR test is 3 percent. However, even if one were willing to accept the hypothesis, inspecting Table 4 reveals that the parameter estimates imply that the small shocks are neutral, whereas the big shocks have real effects; menu-cost theories imply the opposite pattern.

However, we still need to look at Case 7, which introduces the restrictions based on the model of Ball and Mankiw (1994). Again, we test this case against Case 1 because it might not be nested in
Case 3 and/or Case 5.26 The likelihood of this specification is higher than the likelihood of Case 5. The LR test implies that we cannot reject the restrictions and the probability value is as high as 13 percent. Furthermore, the coefficient on small negative shocks is now significant at standard significance levels. This result is somewhat surprising, suggesting that the only monetary shocks that have real effects are small negative ones (i.e., contractionary policies)

${ }^{26}$ Given the evidence from Case 1, we also checked if only big negative shocks have real effects. Case 7 turns out to have a much higher likelihood than this alternative case. 
and that such contractions of monetary policy lower output. Thus, the empirical evidence seems to be in favor of the hybrid asymmetry. In conclusion, the results indicate very strong empirical evidence in favor of the hybrid asymmetry. In one sense, this result provides evidence in favor of the asymmetry hypothesis and shows that one could increase steady-state output by lowering the variance of the monetary policy shocks. Nevertheless, one has to be careful with the interpretation. If the monetary authority were to make monetary policy more predictable, firms might change their pricing policies; this would affect the range of monetary policies that would have real effects. Thus, it is not clear that the policy implication mentioned above holds in this setting.

\section{SUMMARY AND CONCLUSIONS}

Asymmetries in the relationship between real aggregate activity and monetary policy is a phenomenon that can arise under a variety of different assumptions about the economy. The specific version of the asymmetry differs between competing theories, and it is often difficult to test the underlying assumptions directly on macroeconomic data. Furthermore, it is not clear that tests of the assumptions at the household or firm level necessarily carry over to the aggregate level. Since such asymmetric effects in principle can have strong implications not only for the way we think about the macroeconomy, but also for the conduct of economic policy, it thus seems important to empirically examine the evidence on these asymmetries using aggregate data.

In this paper we have focused on the possible asymmetries in the way that different monetary policy shocks affect real aggregate activity. The principal aim of our investigation has been to test indirectly for the asymmetries that may arise in macroeconomic models with menu costs, but the analysis may be thought of more broadly in terms of models with imperfections in goods and labor markets. We highlighted the possible distinctions between different monetary policy shocks that may arise in such models, and we compared these with the traditional Keynesian asymmetry that has been investigated empirically in a number of papers.

In principle, the menu-costs models imply a different type of asymmetric effect than the distinction between positive and negative shocks tested for in previous papers. The most important distinction in basic menu-costs models is between big and small shocks as distinguished either by their size (in a non-stochastic environment) or by their variance (in a stochastic environment). However, with steady-state inflation, there may also be a distinction between positive and negative shocks, but the implied asymmetry is different from the traditional Keynesian asymmetry since the latter does not distinguish shocks by their size.

We developed an empirical framework to distinguish between these competing theories and to test for each of them; we applied this to U.S. postwar data. Our results indicated that, when using M1, the evidence is slightly mixed-since we cannot reject either that shocks are symmetric or that negative shocks have the same effects as positive shocks (but both types of shocks are non-neutral). These results, however, may be hampered by the instability of M1 demand, and we considered the same analysis using the federal funds rate as the monetary policy measure rather than $\mathrm{M} 1$. In these data, which we have more faith in, we found very strong evidence in favor of only small negative shocks having real effects. Thus, the U.S. data seem to indicate evidence in favor of the asymmetry implied by menu-costs models in environments with positive steady-state inflation.

It would be interesting to extend this analysis along two lines. First, one might wish to look into other versions of asymmetric effects. One possible direction could be to look into how economic policy affects output in different phases of the business cycle. Another possibility is to look into the effects of nominal demand shocks and their potential asymmetric effects in stochastic dynamic general equilibrium models. We plan to investigate these matters in future research.

\section{REFERENCES}

Agénor, Pierre-Richard. "Asymmetric Effects of Monetary Policy Shocks.” Working paper, The World Bank, 2001.

Akerlof, George A. and Yellen, Janet L. "A Near-Rational Model of the Business Cycle with Wage and Price Inertia.” Quarterly Journal of Economics, 1985, 100(Suppl 4), pp. 823-38.

Baba, Y.; Hendry, David F. and Starr, Ross M. "The Demand for M1 in the USA, 1960-1988." Review of Economic Studies, January 1992, 59(1), pp. 25-61.

Ball, Laurence and Mankiw, N. Gregory. "Asymmetric Price Adjustment and Economic Fluctuations." Economic Journal, March 1994, 104(423), pp. 247-61. 
Ball, Laurence and Romer, David. "Are Prices Too Sticky?" Quarterly Journal of Economics, August 1989, 104(3), pp. 507-24.

Ball, Laurence and Romer, David. "Real Rigidities and the Non-Neutrality of Money." Review of Economic Studies, April 1990, 57(2), pp. 183-203.

Barro, Robert J. "Unanticipated Money Growth and Unemployment in the United States." American Economic Review, March 1977, 67(2), pp. 101-15.

Barro, Robert J. "Unanticipated Money, Output, and the Price Level in the United States." Journal of Political Economy, August 1978, 86(4), pp. 549-80.

Barro, Robert J. and Hercowitz, Zvi. "Money Stock Revisions and Unanticipated Money Growth." Journal of Monetary Economics, April 1980, 6(2), pp. 257-67.

Barro, Robert J. and Rush, Mark. "Unanticipated Money and Economic Activity," in Stanley Fischer, ed., Rational Expectations and Economic Policy. Chicago: University of Chicago Press, 1980.

Belongia, Michael T. "Measurement Matters: Recent Results from Monetary Economics Reexamined." Journal of Political Economy, October 1996, 104(5), pp. 1065-83.

Bernanke, Ben S. and Gertler, Mark. "Agency Costs, Net Worth, and Business Fluctuations." American Economic Review, March 1989, 79(1), pp. 14-31.

Blanchard, Olivier J. and Kiyotaki, Nobuhiro. "Monopolistic Competition and the Effects of Aggregate Demand." American Economic Review, September 1987, 77(4), pp. 647-66.

Boschen, John F. and Grossman, Herschel I. "Tests of Equilibrium Macroeconomics Using Contemporaneous Monetary Data." Journal of Monetary Economics, November 1982, 10(3), pp. 309-33.

Caballero, Ricardo J. and Engel, Eduardo M.R.A. "Microeconomic Rigidities and Aggregate Price Dynamics." European Economic Review, May 1993, 37(4), pp. 697-711.

Christiano, Lawrence J.; Eichenbaum, Martin and Evans, Charles. "The Effects of Monetary Policy Shocks: Evidence from the Flow of Funds." Review of Economics and Statistics, February 1996, 78(1), pp. 16-34.
Cover, James Peery. "Asymmetric Effects of Positive and Negative Money-Supply Shocks." Quarterly Journal of Economics, November 1992, 107(4), pp. 1261-82.

DeLong, J. Bradford and Summers, Lawrence H. "How Does Macroeconomic Policy Affect Output?" Brookings Papers on Economic Activity, 1988, (2), pp. 433-94.

Demery, David. "Asymmetric Effects of Money on Real Output: Evidence for the UK." Unpublished manuscript, University of Bristol, 1993.

Garcia, Rene and Schaller, Huntley. "Are the Effects of Monetary Policy Asymmetric?” Unpublished manuscript, Université de Montréal, 1995.

Gertler, Mark. "Financial Capacity and Output Fluctuations in an Economy with Multi-Period Financial Relationships." Review of Economic Studies, July 1992, 59(3), pp. 455-72.

Greenwald, Bruce C. and Stiglitz, Joseph E. "Financial Market Imperfections and Business Cycles." Quarterly Journal of Economics, February 1993, 108(1), pp. 77-114.

Hamilton, James D. "Rational-Expectations Econometric Analysis of Changes in Regime: An Investigation of the Term Structure of Interest Rates." Journal of Economic Dynamics and Control, June/September 1988, 12(2/3), pp. 385-423.

Hamilton, James D. "A New Approach to the Economic Analysis of Non-Stationary Time Series and the Business Cycle." Econometrica, March 1989, 57(2), pp. 357-84.

Hamilton, James D. "Analysis of Time Series Subject to Changes in Regime.” Journal of Econometrics, July-August 1990, 45(1/2), pp. 39-70.

Hamilton, James D. “The Daily Market for Federal Funds." Journal of Political Economy, February 1996, 104(1), pp. 26-56.

Hamilton, James D. Time Series Analysis. Princeton, NJ: Princeton University Press, 1994.

Hooker, Mark A. "What Happened to the Oil PriceMacroeconomy Relationship?" Journal of Monetary Economics, October 1996, 38(2), pp. 195-213.

Hooker, Mark A. and Knetter, Michael M. "The Effects of Military Spending on Economic Activity: Evidence from State Procurement Spending." Working Paper, Wellesley College, 1996. 
Kandil, Magda. "Asymmetry in the Effects of Monetary and Government Spending Shocks: Contrasting Evidence and Implications." Economic Inquiry, April 2002, 40(2), pp. 288-313.

Karras, Georgios. "Are the Output Effects of Monetary Policy Asymmetric? Evidence from a Sample of European Countries." Oxford Bulletin of Economics and Statistics, May 1996, 58(2), pp. 267-78.

Lo, Ming Chien and Piger, Jeremy. "Is the Response of Output to Monetary Policy Asymmetric? Evidence from a Regime-Switching Coefficients Model." Working Paper 2001-022, Federal Reserve Bank of St. Louis, July 2003.

Lucas, Robert E. Jr. "Expectations and the Neutrality of Money." Journal of Economic Theory, April 1972, 4(2), pp. $103-24$.

Lucas, Robert E. Jr. "An Equilibrium Model of the Business Cycle.” Journal of Political Economy, December 1975, 83(6), pp. 1113-44.

Macklem, Tiff; Paquet, Alain and Phaneuf, Louis. "Asymmetric Effects of Monetary Policy: Evidence from the Yield Curve.” CREFE Working Paper No. 42, Université de Montréal,1996.

Mankiw, N. Gregory. "Small Menu Costs and Large Business Cycles: A Macroeconomic Model of Monopoly." Quarterly Journal of Economics, May 1985, 10(2), pp. 529-38.

Mishkin, Fredric C. "Does Anticipated Policy Matter? An Econometric Investigation.” Journal of Political Economy, February 1982, 90(1), pp. 22-51.

Parker, Randall E. and Rothman, Philip. "An Examination of the Asymmetric Effects of Money Supply Shocks in the Pre-World War I and Interwar Periods." Working paper, East Carolina University, 2000.

Phillips, Kerk L. "A Two-Country Model of Stochastic Output with Changes in Regime." Journal of International Economics, August 1991, 31(1-2), pp. 121-42.
Ravn, Morten O. and Sola, Martin. "Stylized Facts and Regime Changes: Are Prices Procyclical?” Journal of Monetary Economics, December 1995, 36(3), pp. 497-526.

Ravn, Morten O. and Sola, Martin "A Reconsideration of the Empirical Evidence on the Asymmetric Effects of Money Supply Shocks: Positive vs. Negative or Big vs. Small?" Unpublished manuscript, University of Aarhus, Denmark, March 1996.

Ravn, Morten O. and Sola, Martin "Business Cycle Dynamics: Predicting Transitions with Macro Variables." Unpublished manuscript, Universitat Pompeu Fabra, 1997.

Senda, Takashi. "Asymmetric Effects of Money Supply Shocks and Trend Inflation." Journal of Money, Credit, and Banking, February 2001, 33(1), pp. 65-89.

Sensier, Marianne. "The Asymmetric Effect of Monetary Policy in the UK." Working paper, University of Oxford, 1996.

Shleifer, Andrei and Vishny, Robert W. "Liquidation Values and Debt Capacity: A Market Equilibrium Approach." Journal of Finance, September 1992, 47(4), pp. 1343-66.

Sola, Martin and Driffill, E. John. "Testing the Term Structure of Interest Rates Using a Stationary Vector Autoregression with Regime Switching." Journal of Economic Dynamics and Control, May-July 1994, 18(3/4), pp. 601-28.

Stock, James H. and Watson, Mark W. "A Simple Estimator of Cointegrating Vectors in Higher Order Integrated Systems." Econometrica, July 1993, 61(4), pp. 783-820.

Weise, Charles L. "The Asymmetric Effects of Monetary Policy: A Nonlinear Vector Autoregression Approach." Journal of Money, Credit, and Banking, February 1999, 33(1), pp. 85-108. 


\section{Appendix}

\section{DATA DESCRIPTION}

All variables studied in this paper are sampled at the quarterly frequency and were de-seasonalized from the source. The first set of data was kindly supplied by James Peery Cover and is described in detail in Cover (1992). The sample period covers 1948:Q1-1987:Q4. The variables used here are defined as follows:

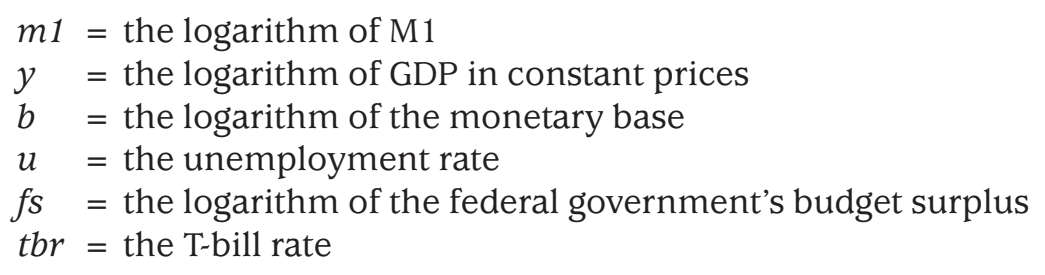

The second set of data corresponds to the data set studied in Christiano, Eichenbaum, and Evans (1996). These data were obtained from the Datastream database. The sample period covers 1959:Q3-1995:Q3. The variables used here are defined as follows:

$-f f=$ the negative of the federal funds rate

$y=$ the logarithm of GDP in constant prices

$n b r=$ the logarithm of the sum of non-borrowed reserves and extended credit

py $=$ the logarithm of the implicit GDP deflator

trs $=$ the logarithm of total reserves

$t b r=$ the T-bill rate

\section{THE FILTER}

It is assumed that one of the variables included in the filter is governed by a scalar state variable. The other variable(s) is (are) not allowed to switch and is (are) de-meaned. The filter involves the following five steps.

Step 1. Let $y$ and $x$ be the variables that are observed, and let $s$ be the unobserved state variable. Calculate the density of the $m$ past states and the current state conditional on the information included in $y_{t-1}, x_{t-1}$ and all past values of $y$ and $x$ :

$$
\begin{aligned}
& p\left(s_{t}, s_{t-1}, s_{t-m} \mid y_{t-1}, y_{t-2},, y_{0}, x_{t-1}, x_{t-2}, x_{0}\right) \\
& =p\left(s_{t} \mid s_{t-1}\right) p\left(s_{t-1}, s_{t-2}, s_{t-m} \mid y_{t-1}, y_{t-2}, y_{0}, x_{t-1}, x_{t-2}, x_{0}\right),
\end{aligned}
$$

where $p\left(s_{t} \mid s_{t-1}\right)$ is the transition probability matrix of the states that are assumed to follow a Markov process. As in all subsequent steps, the second term on the right-hand side is known from the preceding step of the filter. In the present case the probability on the left-hand side of equation (A.1) is known from the input to the filter, which in turn represents the result of the iteration at date $t-1$ (from step 5 described below).

Initial values for the parameters and the initial conditions for the Markov process are required to start the filter. The unconditional distribution, $p\left(s_{m}, s_{m-1}, s_{0}\right)$, has been chosen for the first observation.

Step 2. Calculate the joint conditional density of $y_{t}$ and $\left(s_{t}, s_{t-1}, s_{t-m}\right)$,

$$
\begin{aligned}
& p\left(y_{t}, s_{t}, s_{t-1}, s_{t-m} \mid y_{t-1}, y_{t-2},, y_{0}, x_{t-1}, x_{t-2},, x_{0}\right) \\
& =p\left(y_{t} \mid s_{t}, s_{t-m}, y_{t-1}, y_{0}, x_{t-1}, x_{0}\right) p\left(s_{t}, s_{t-m} \mid y_{t-1}, y_{0}, x_{t-1}, x_{0}\right),
\end{aligned}
$$

where we assume that

$$
\begin{aligned}
& p\left(y_{t}, s_{t}, s_{t-1}, s_{t-m} \mid y_{t-1}, y_{t-2}, y_{0}, x_{t-1}, x_{t-2}, x_{0}\right) \\
& =\frac{1}{(2 \pi)^{0.5}\left(\sigma_{0}+\Delta \sigma s_{t}\right)} \exp \left(-\left(2\left(\sigma_{0}+\Delta \sigma s_{t}\right)^{2}\right)^{-1} u_{s t}^{2}\right)
\end{aligned}
$$


where

$$
u_{s t} \equiv y_{t}-\left(\mu_{0}+\Delta \mu s_{t}\right)-\Phi(L)\left(y_{t}-\left(\mu_{0}+\Delta \mu s_{t}\right)\right)-\Theta(L) x_{t} .
$$

It should be noted that $p\left(y_{t} \mid s_{t}, s_{t-m}, y_{t-1}, y_{0}, x_{t-1}, x_{0}\right)$ involves $\left(s_{t}, s_{t-m}\right)$, which is a vector that can take on $2^{m+1}$ values.

Step 3. Marginalize the previous joint densities with respect to the states, which give the conditional density from which the (conditional) likelihood function is calculated:

$$
p\left(y_{t} \mid y_{t-1}, y_{0}, x_{t-1}, x_{0}\right)=\sum_{s_{t}=0}^{1} \sum_{s_{t-1}=0}^{1} \ldots \sum_{s_{t-m}=0}^{1} p\left(y_{t}, s_{t}, s_{t-m} \mid y_{t-1}, y_{0}, x_{t-1}, x_{0}\right) .
$$

Step 4. Combining the results from steps 2 and 3, calculate the joint density of the state conditional on the observed current and past realizations of $y$ :

$$
p\left(s_{t}, s_{t-1}, s_{t-m} \mid y_{t}, y_{0}, x_{t},, x_{0}\right)=\frac{p\left(y_{t}, s_{t}, s_{t-m} \mid y_{t-1}, y_{0}, x_{t-1}, x_{0}\right)}{p\left(y_{t} \mid y_{t-1},, y_{0}, x_{t-1}, x_{0}\right)} .
$$

Step 5. The desired output is then obtained from

$$
p\left(s_{t}, s_{t-1}, s_{t-m+1} \mid y_{t},, y_{0}, x_{t},, x_{0}\right)=\sum_{s_{t-m}=0}^{1} p\left(s_{t}, s_{t-1}, s_{t-m} \mid y_{t}, y_{0}, x_{t},, x_{0}\right) .
$$

The output of step 5 is used as an input to the filter in the next iteration. Estimates of the parameters are calculated by maximizing the sample likelihood, which can be calculated from step 3. 